\title{
Criteria for the assessment of visual word processing
}

Carina Pinto ${ }^{1}$, Alina Villalva ${ }^{1,2}$

${ }^{1}$ Linguistic Center of University of Lisbon, Portugal

${ }^{2}$ Department of General and Romance Linguistics, University of Lisbon, Portugal

https://doi.org/10.36505/ExLing-2018/09/0022/000355

\begin{abstract}
Our paper aims to verify the role of different criteria, namely, number of syllables; number of morphological constituents; type of morphological structure and word frequency, in the visual word processing. We used a priming paradigm with a lexical decision task. The subjects were exposed to a verb prime (e.g. doar 'to donate') for 50 $\mathrm{ms}$, immediately followed by the deverbal derivative in -cão (e.g. doação 'donation'). The results show that (i) there are no significant differences related to the number of morphological constituents; (ii) there are significant differences between pairs with 5syllable primes and 2-syllable or 4-syllable primes; (iii) the morphological structure of the verb yields a significant difference between identity and lexicalized pairs; and (iv) frequency triggers significant differences.

Key words: Visual word processing; morphological priming, morphological complexity, frequency of use.
\end{abstract}

\section{Introduction}

Our current research aims to compare different criteria for the assessment of visual word processing (VWP). We are interested in morphological processing and lexical access, but in order to develop any experiment in those fields, we need to ensure that the adopted methodology will produce results that are related to morphological issues and not to phonological or phonetic features, nor to semantic properties or word frequency effects.

A commonly reported result in studies that use the morphological priming paradigm is the facilitation of word recognition when the target is preceded by a morphologically related word. In order to confirm this hypothesis, researchers build word lists that include several control factors that will allow them to claim that the output results are due to morphological, orthographic, or semantic properties, and not to properties such as frequency, word length, age of acquisition, among others.

Balota et al. (2004) report that there are several problems when we try to control the various psycholinguistic variables. The authors state that it is difficult to select words that vary only in one dimension, since these

ExLing 2018: Proceedings of 9th Tutorial and Research Workshop on Experimental Linguistics, 28-30 August, Paris, Frannce 
variables are highly correlated. The smallest words tend to be the most frequent, to have a simple morphological structure and they are those that are acquired earlier. Another problem rises from the tendency to choose items that are located in extreme positions in a particular variable. For example, a given word is typically compared to both a highly frequent and a non-frequent one. Consequently, the behaviour of the target item is distinct at both ends. The authors thus claim that variables such as frequency must be continuous rather than dichotomous.

Many of the visual recognition models, as well as a large majority of the studies associated with them, have been developed on data from English, a language that has a poor morphological system. Our study analyses Portuguese data that has a richer morphological system. A global and systematic approach to the knowledge of the Portuguese morphological system of Portuguese seems to be essential for the observation of morphological processing of Portuguese words. Therefore, we have adopted Villalva $(1994,2000,2008)$ as the framework for the definition of the morphological conditions that we want to analyse. Furthermore, the experiment presented below was designed in the framework of the mixed models of VWP that argue that the path chosen to access complex words depends on frequency, size and familiarity among other word properties (cf. Baayen at al., 1997; Domínguez et al., 2000).

\section{Method}

We have used a priming paradigm with a lexical decision task and we have tested 34 healthy college students $\left(\mathrm{M}_{\text {age }}=21,74 \pm 5,1\right)$. The subjects were exposed to a verb prime (e.g. doar 'to donate') for $50 \mathrm{~ms}$, immediately followed by the deverbal derivative in -ção (e.g. doação 'donation'), available until the lexical decision was made.

We have set four dependent variables:

a) number of syllables (prime): from 2 to 5 (e.g. do-ar, a-cu-sar, u-ti-li-zar, so-cia-a-lizar);

b) number of morphological constituents (prime), disregarding morphological specifiers: from 1 to 3 (e.g. [do]ar, [[util][iz]]ar 'to use'; [[[soci][al]][iz]]ar 'to socialize');

c) type of morphological structure (prime): simple vs complex; compositional vs. complex lexicalized (e.g. doar, utilizar, idealizar). In this case, we have also presented an identity condition (e.g. DOAÇÃO)/doação);

d) word frequency (prime and target), considered as a continuous, nondichotomic, variable. 
Priming material contains (i) 38 identity pairs; (ii) 34 pairs formed by prime words that exhibit a different number of syllables; (iii) 38 pairs with a different number of morphological constituents in the prime; and (iv) 33 pairs with different morphological structure of the prime. We have also introduced 77 pairs of WORD/pseudo word as fillers.

\section{Results}

We have performed an exclusion of the data that had reaction time values above $2000 \mathrm{~ms}(3,19 \%)$. Preliminary results show an error percentage of $2,5 \%$. Considering the dependent variable number of prime syllables, these errors occur mainly in pairs where the prime was 3 syllables $(50 \%)$, followed by the pairs with 5 syllables $(20,8 \%)$, and pairs with 4 syllables $(16,7 \%)$. The pairs with fewer errors were those that have a 2-syllable prime (12,5\%). Regarding the number of morphological constituents, the pairs that yield more wrong replies $(68,8 \%)$ include a prime that has only one morphological constituent $(10,4 \%$ of wrong replies with 2 morphological constituents; and 4,2\% with 3 constituents). Finally, derivatives primed by a simplex base have a $60,4 \%$ of wrong replies, while compositional derived bases have $16,7 \%$ and lexicalised derivatives have $6,3 \%$. The identity condition behaves like compositional derived bases.

The remaining results regard exclusively correct replies. The most prominent results considering the reactions times (RTs) are the following:

- There are no significant differences between pairs with different number of morphological constituents $(F=1,269, p=0,281)$;

- Considering the morphological structure of the prime, there are significant differences between conditions $(F=2,815, p=0,038)$, being that difference between identity pairs and lexicalized pairs $(\mathrm{t}=$ $2,415, \mathrm{p}=0,016)$;

- There are significant differences in the between the pairs with different number of syllables $(F=5,509, p=0,004)$, but that difference it's only between pairs were the prime has 5 syllables and the other pairs (difference from 2 syllables: $t=-2,799, p=0,005$; and from 4 syllables: $\mathrm{t}=-2980 ; \mathrm{p}=0,003)$;

- Finally, the results show that the frequency of the base produces significant differences in the RTs $(\mathrm{F}=2,814, \mathrm{p}=0,000)$ and the same for the frequency of the target $(F=2,730, p=0,000)$. These results need further analysis that may consider several stages of frequencies (lower, median and higher, for example). 
These results correspond to the first stage of development of the experiment and they will help us to detect methodological issues and to stage some hypothesis about the role of morphology in VWP.

\section{Discussion}

We have concluded that (i) there are no significant differences related to the number of morphological constituents; (ii) there are significant differences between pairs with 5-syllable primes and 2-syllable or 4syllable primes; (iii) the morphological structure of the verb yields a significant difference between identity and lexicalized pairs; and (iv) frequency triggers significant differences.

These results are still preliminary, but they allow us to hypothesize that the number of morphological constituents per se is not a relevant criterion in VWP. Compositionality seems to be more relevant, particularly if lexicalized derivatives are considered. Finally, frequency is a very relevant criterion, but we need to recalibrate our data, taking degrees into account (low, medium and high, for instance). In sum, the word length seems to be irrelevant (unless we select 5-syllable words); the number of morphological constituents is equally unimportant; but the familiarity and the word semantic transparency (or opacity) need to be considered. These results may legitimate further experiments that neglect contrasts between words with 2, 3 and 4 syllables, and 1, 2 or 3 morphological constituents. Conversely, they confirm that the contrasts between familiar and unfamiliar words and lexicalized derived words and compositional derivatives cannot be disregarded.

\section{References}

Baayen, H., Dijkstra, T., Schreuder, R. 1997. Singulars and Plurals in Dutch: Evidence for a Parallel Dual- Rout Model. Journal of Memory and Language 37, 94-117. doi: 10.1006/jmla.1997.2509.

Domínguez, A., Cuetos, F., Segui, J. 2000. Morphological processing in word recognition: A review with particular reference to Spanish data. Psicológica 21, 375 401. doi: 10.1.1.16.8654

Balota, D.A., Cortese, M.J., Sergent-Marshall, S.D., Spieler, D.H., Yap, M.J. 2004. Visual word recognition of single-syllable words. Journal of Experimental Psychology: General, 133, 283-316. doi: 10.1037/0096-3445.133.2.283.

Villalva, A. 1994. Estruturas Morfológicas. Unidades e Hierarquias nas Palavras do Português. Universidade de Lisboa: Dissertação de Doutoramento.

Villalva, A. 2000. Estruturas Morfológicas. Unidades e Hierarquias nas Palavras do Português. Lisboa: FCT-FCG. ISBN 9789723108743.

Villalva, A. 2003. Aspectos morfológicos da gramática do Português. In Mateus, M.H., Brito, A.M., Duarte, I., Faria, I.H. (Eds), Gramática do Português. Lisboa: Caminho.

Villalva, A. 2008. Morfologia do Português. Lisboa: Universidade Aberta. 